\title{
Seismic fragility of a highway bridge in Quebec retrofitted with natural rubber isolators
}

\section{Fragilidade sísmica de uma ponte rodoviária em Quebec reabilitada com isoladores em borracha natural}
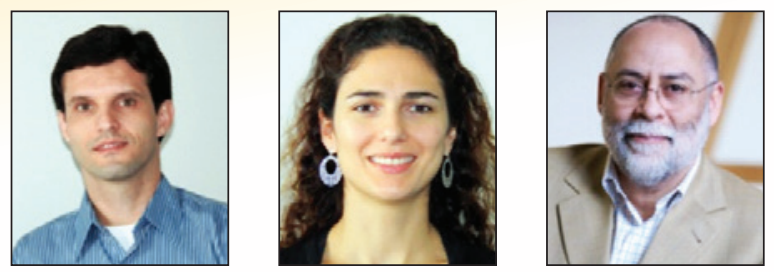

G. H. SIQUEIRA a siqueira@fec.unicamp.br

D. H. TAVARES

danusaht@gmail.com

P. PAULTRE ${ }^{c}$ Patrick.Paultre@Usherbrooke.ca

\begin{abstract}
This paper presents fragility curves for the evaluation of a highway bridge retrofitted with seismic isolator devices. The object of this study is the Chemin des Dalles bridge over Highway 55 located in Trois-Rivières in Quebec, Canada. A series of synthetic ground motions time histories compatible with eastern Canada are used to capture the uncertainties related to the hazard. The seismic isolator model represents natural rubber bearing placed under the longitudinal girders over the bents and the abutments of the bridge. NRB isolators are placed in these locations to uncouple the movement of the superstructure and the infrastructure, increasing the flexibility of the system and decreasing the forces transmitted to the infrastructure. Finally, a set of fragility curves for the as-built and retrofitted models are compared to evaluate the effectiveness of seismic isolation to decrease the seismic vulnerability of this bridge.
\end{abstract}

Keywords: fragility curves; seismic isolation; vulnerability, highway bridges.

\section{Resumo}

Neste trabalho são apresentadas curvas de fragilidade para o estudo da reabilitação de uma ponte rodoviária utilizando isoladores sísmicos. O objeto deste estudo é a ponte Chemin des Dalles que fica sobre a Rodovia 55 e está localizada na cidade de Trois-Rivières na província de Quebec, Canadá. Uma série de acelerogramas artificiais de terremotos compatíveis com a região leste do Canada foi utilizada com o intuito de reproduzir as incertezas quanto à natureza dos eventos sísmicos na região. O modelo do sistema de isolação representa isoladores em borracha natural colocados entre as longarinas e as transversinas e sobre os encontros da ponte. A disposição destes elementos desacopla os movimentos da superestrutura e da infraestrutura, aumentando a flexibilidade do sistema reduzindo assim os esforços transmitidos à infraestrutura. Finalmente, as curvas de fragilidade para os modelos da ponte real e reabilitada foram comparadas evidenciando a efetividade do sistema de isolação para diminuir a vulnerabilidade sísmica desta ponte.

Palavras-chave: curvas de fragilidade, isolação sísmica, vulnerabilidade, pontes.

Département de Génie Civil, Faculté de Génie, Université de Sherbrooke, Sherbrooke, QC, Canada. 


\section{Introduction}

Recent earthquake damages revealed bridges as the most vulnerable component of the transportation system. The disruption of the traffic transportation after an earthquake can significantly impact the economy of the region, in addition to the potential loss of lives. In light of the significant earthquake damage in a large number of bridges seismically deficient [1], there is a need to perform adequate assessment of the vulnerability of these structures. In the case of bridges in Quebec, a moderate seismic region, $75 \%$ of these structures are more than thirty years old [2], and consequently, they were built with a lack of seismic design details. Moreover, the design level event was increased across Canada in 2005 by the adoption of a uniform hazard spectrum with a probability of exceedance of $2 \%$ in 50 years (2475-years return period). Recently, Tavares et al. [3] have assessed the seismic vulnerability of typical configurations of bridges in Quebec, demonstrating that a large number of bridges may be significantly damaged after an earthquake corresponding to the design level event adopted in Canada.

Fragility curves are useful tools for assessing the vulnerability of bridges, describing the conditional probability that a structure or a structural component will meet or exceed a specific damage state for various levels of ground shaking. In addition, fragility curves provide an effective way to evaluate prospective retrofit measures that aim to reduce the seismic risk and can also be used in the development of a post-event action plan [4]. They have been derived using empirical data $[5,6]$ or analytical approaches [7-10], mainly for as-built bridge configurations. There is still a lack of studies to assess the seismic vulnerability of typical bridge configurations after retrofitting and a limited number of studies have been conducted to evaluate different retrofit techniques [11, 12, 13].

The object of this study is the Chemin des Dalles Bridge over Highway 55 located near Trois-Rivières, Quebec, Canada, presented in Figure 1. This bridge was designed in 1975 and it's not in accordance with the latest edition of the Canadian Bridge Design Code [14] procedures for seismic events and the design event level adopted in Canada [15]. Dynamic tests in situ were performed in a previous work by the Earthquake Engineering and Structural Dynamics Research Center (CRGP) located at the University of Sherbrooke, to determine the natural frequencies, mode shapes and damping of the Chemin des Dalles bridge. Roy et al. [16] performed pseudo-dynamic tests in a 1/2.95 scaled prototype bent of this bridge retrofitted using carbon-fiber-reinforced polymers (CRFPs) and a substructuring approach in the numerical model of the remaining elements. Recently, Tavares et al. [17] conducted a probabilistic performance assessment of the same bridge using fragility curves at the component level and system level to this bridge on the transverse direction. The results showed that the bridge fragility was governed by the vulnerability of its columns for this structure.

In this study, fragility curves are used to assess the seismic vulnerability and to evaluate the efficacy of seismic isolation as a retrofit measure to the Chemin des Dalles Bridge. Natural rubber seismic isolation devices are selected as the retrofit measure due to the practicality to replace the conventional elastomeric bearing system without major changes in the bridge configuration [18]. Results of the fragility analysis of the as-built and retrofitted bridge models are compared to evaluate the effectiveness of the retrofitting measure for various levels of ground motion shaking and damage states.

\section{Retrofit using seismic isolation}

Over the last few years, seismic isolation has been used in an effort to mitigate or eliminate the damage in structural elements and systems during severe earthquake ground motion. The concept is quite simple and consists basically in introducing flexibility to the structural system, normally between superstructure and bents or abutments, increasing the natural periods of vibration, thus, reducing the amount of the seismic energy input into the system. Figure 2 illustrates this concept for bridges. The most widely accepted concept of seismic isolation uses elastomeric bearings [19]. Moreover, retrofit measures with focus on the superstructure, as seismic isolation, are generally less expensive and easier to be applied

\section{Figure 1 - Chemin des Dalles bridge}

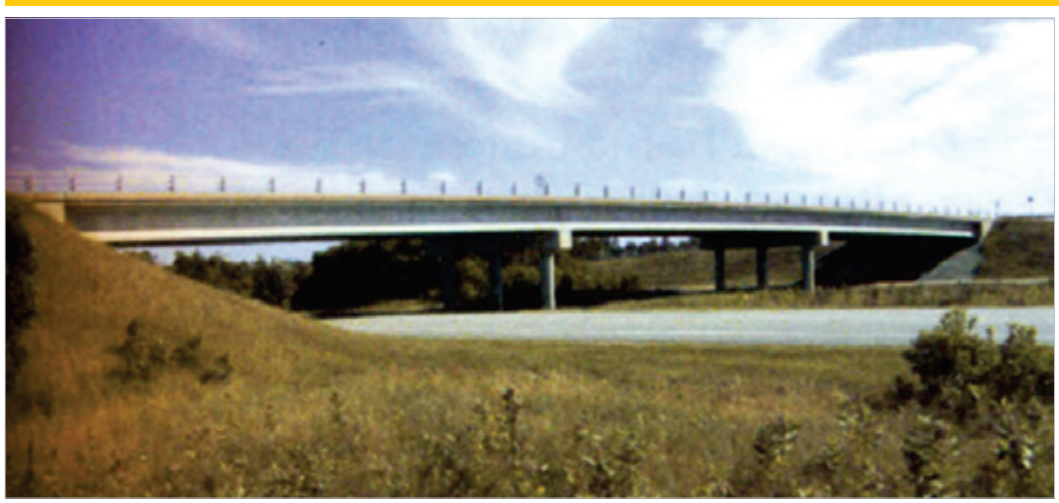

General view

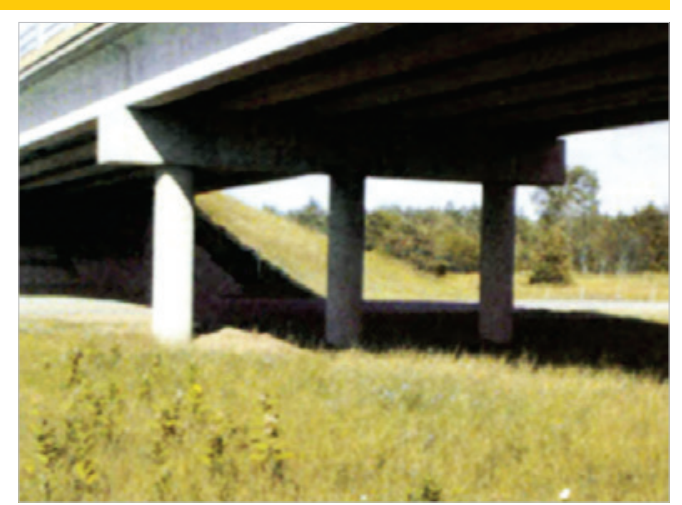

B Bent view 


\section{Figure 2 - Concept of seismic isolation for bridges}

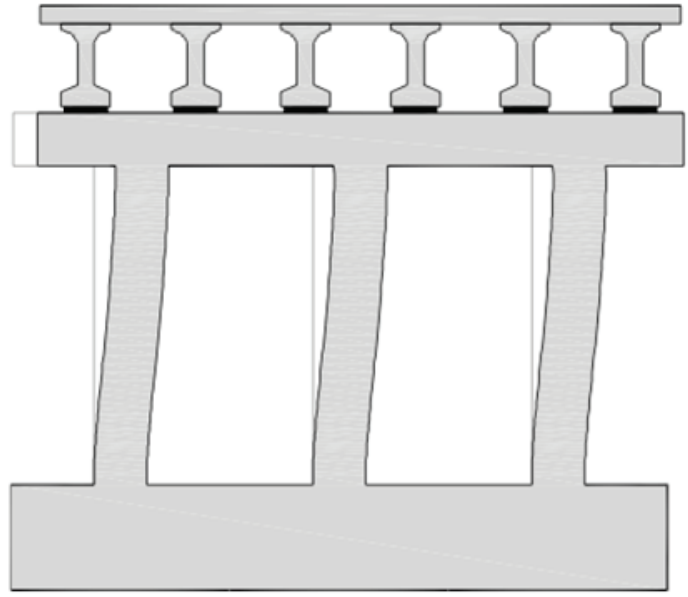

A As-built

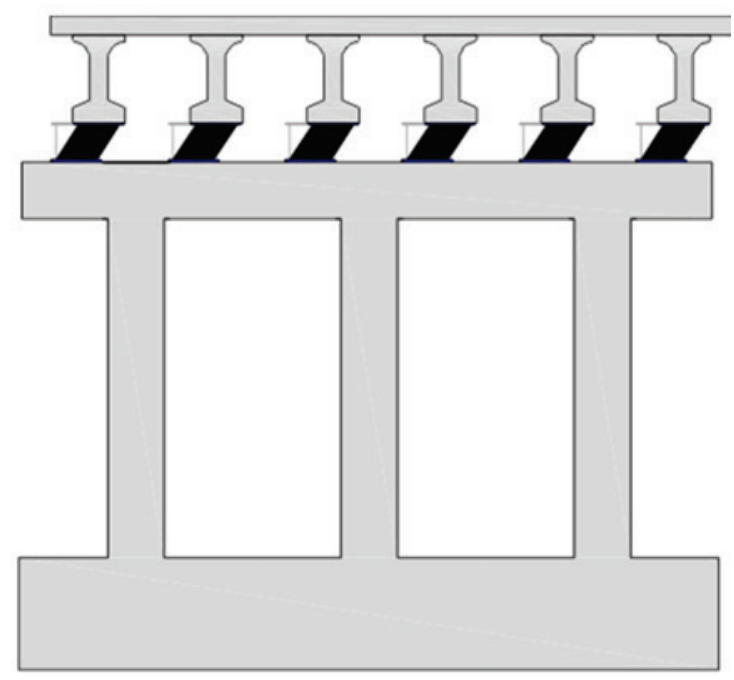

B Isolated compared to retrofits for columns or foundations [20]. The increase of the system flexibility and lengthen of the natural period result in the increase of the superstructure displacements. Another issue related to flexible structures is the small resistance to service-level loads, such as wind and braking forces. To control these undesirable effects, damping properties of the rubber can be increased or a lead plug that increases the energy dissipation capacity and initial stiffness of the bearing devices can be used.
Depending on their configuration, the elastomeric seismic isolation devices can be grouped in: (a) Natural Rubber Bearings (NRB); (b) High-damping Rubber Bearings (HDRB); and (c) Lead-rubber bearings (LRB). The typical elastomeric seismic isolator devices are presented in Figure 3. The most important properties of the elastomeric bearing devices are shear and compressive moduli, tensile strain and strength and hysteretic energy dissipation. Usually, conventional elastomeric bearings are identified through their

\section{Figure 3 - Elastomeric isolation devices}

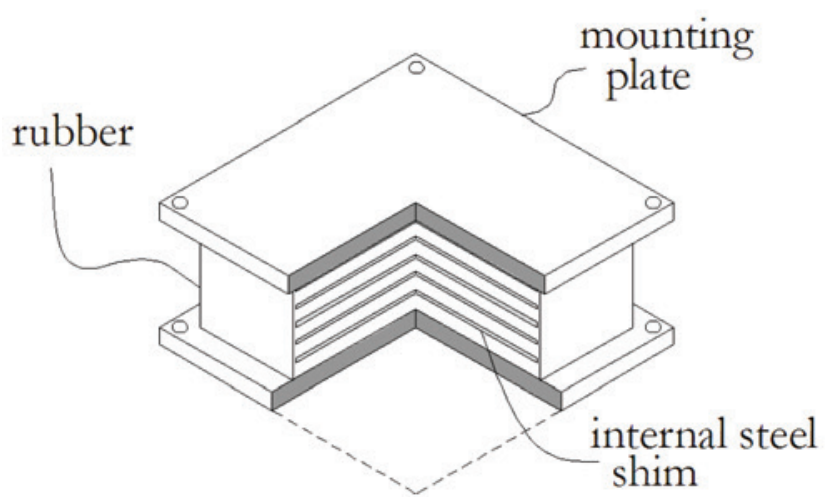

A NRB / HDRB

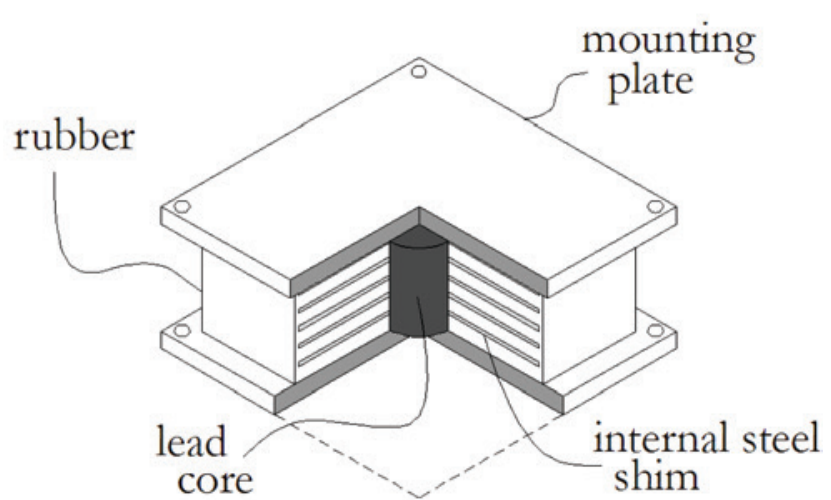

B LRB 
hardness, which can be easily measured and is directly related to primary physical properties [18]. For the design of seismic isolators, these properties should be verified by tests $[14,21]$. In practice, the range of hardness considered is 50 to 70 (shore $A$ ) and the range of shear modulus is 0.4 to $1.4 \mathrm{MPa}$. The equivalent viscous damping varies from 5 to $10 \%$ for natural rubber and from 10 to $25 \%$ for high-damping rubber and lead-rubber bearings. For systems with equivalent viscous damping greater than $30 \%$, special attention shall be taken in the seismic analysis for the isolated system [21]. The effective shear stiffness for rubber devices can be estimated by a linear elastic relationship that is given by Equation 1 . Where $G$ is the shear modulus, $A$ is the cross sectional area, $T$ is the total thickness of rubber in the bearing. In practice, the viscouselastic behavior of isolation bearings is modeled by a bilinear model based on the three parameters $\mathrm{K}_{1}, \mathrm{~K}_{2}$, and $\mathrm{Q}$, as presented in Figure 4 [22].

$$
K_{e f f}=\frac{G A_{r}}{T_{r}}
$$

The elastic stiffness $\left(K_{1}\right)$ is obtained from available hysteresis loop of rubber bearing tests or as a multiple of the $\mathrm{K}_{2}$ in the case of the lead-rubber bearings. The characteristic strength $(\mathrm{Q})$ is estimated from available hysteresis loop for elastomeric bearings and is given by the yield stress in the lead core for lead-rubber bearings. The postyield stiffness $\left(\mathrm{K}_{2}\right)$ can be estimated from available hysteresis loop or predicted based on the effective stiffness, characteristic strength and maximum displacement [22]. Based on characterization tests of elastomeric rubber bearings [23], the yield displacement $\left(D_{y}\right)$ can be assumed as $10 \%$ of the total elastomer height. Usually, $K_{1}$ varies in the range of 2 to $15 K_{2}$ [24] for NRB/HDRB and 15 to $30 \mathrm{~K}_{2}$ for LRB [25]. In design, the shape factor (S) is an important parameter defined as the ratio of the loaded area by the force-free area for bulging of one bearing layer. For rectangular bearings, the shape factor can be estimated by Equation 2 . Where $I_{1}$ and $I_{2}$ are the plan dimensions of the rectangular bearing, and $t$

\section{Figure 4 - Example of a bilinear model representation}

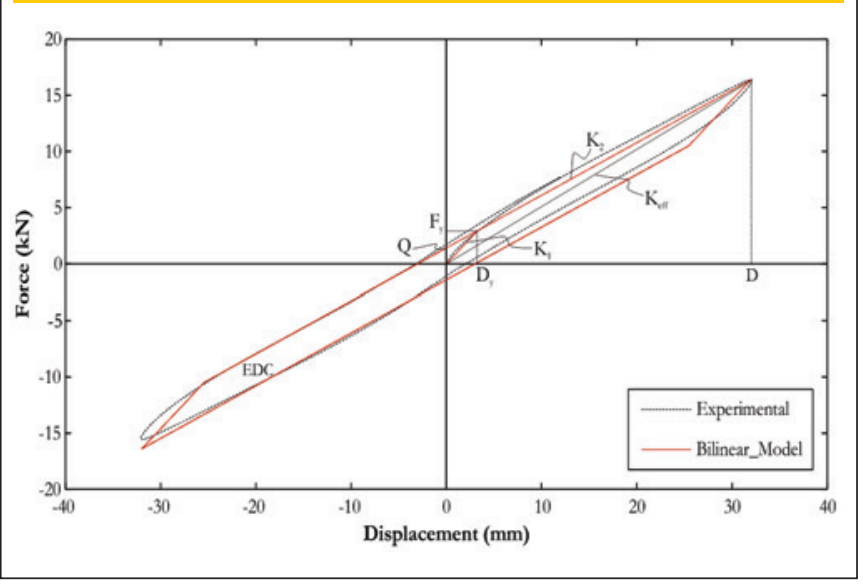

is the thickness of one rubber layer. Generally, the value of S varies between 8 and 20. Smaller values of $S$ are considered only for conventional elastomeric bearings. For bearings with shape factor around 10, the compressibility of rubber is not an important factor to calculate the compressive stiffness and may be neglected [26].

$$
S=\frac{l_{1} \times l_{2}}{2 t\left(l_{1} \times l_{2}\right)}
$$

The maximum displacement and the period of vibration for the isolated system can be calculated from Equations 3 and 4, respectively. In the case of Equation 3, a detailed explanation on the zonal coefficient ratio $(A)$, the site coefficient $\left(S_{j}\right)$, and the damping coefficient $(B)$ can be found in [14] and [21]. To calculate the period of vibration (Eq. 4), the effective stiffness $\left(K_{\text {eff }}\right)$ account for all bearings and substructures supporting the superstructure segment.

$$
d_{i}=\frac{250 A S_{i} T_{e}}{B}
$$

$$
T_{e}=2 \pi \sqrt{\frac{W}{K_{e f f} g}}
$$

In seismic isolation, the isolated period should be at least three times the structural natural period of vibration. One can choose the target period and calculate the effective stiffness, then, choose the dimensions of the seismic isolation devices. Elastomeric seismic devices must be checked for instability in both undeformed and deformed configurations. It should be demonstrated, by tests or analyses, that the elastomeric devices are stable under the imposed axial loads [14].

\section{Methodology}

The methodology used in this paper for the development of fragility curves is based on the component level approach presented by Nielson and DesRoches [27]. A schematic representation of the methodology adopted is depicted in Figure 5. There are three different parts in the fragility curves development. The first concerns the bridge representation; the second represents the solicitation; and the third consists of the performance objectives or limit states. The bridge representation is defined by the numerical model of the Chemin des Dalles bridge. The solicitation is defined by the suite of representative ground motions of eastern Canada. Performance objectives or limit states represent structural capacity, being defined based on expert judgments, experimental data or analytical modes. In the development of fragility curves, the limit states are related to structural capacity (C) and the response of the bridge to ground motion with the seismic demand (D), usually represented as lognormal distributions due to their random natures. Fragility or probability of failure can be defined as the conditional probability that the seismic demand meets or exceeds the structural capacity as 


\section{Figure 5 - Analytical fragility curve methodology to the Chemin des Dalles Bridge}

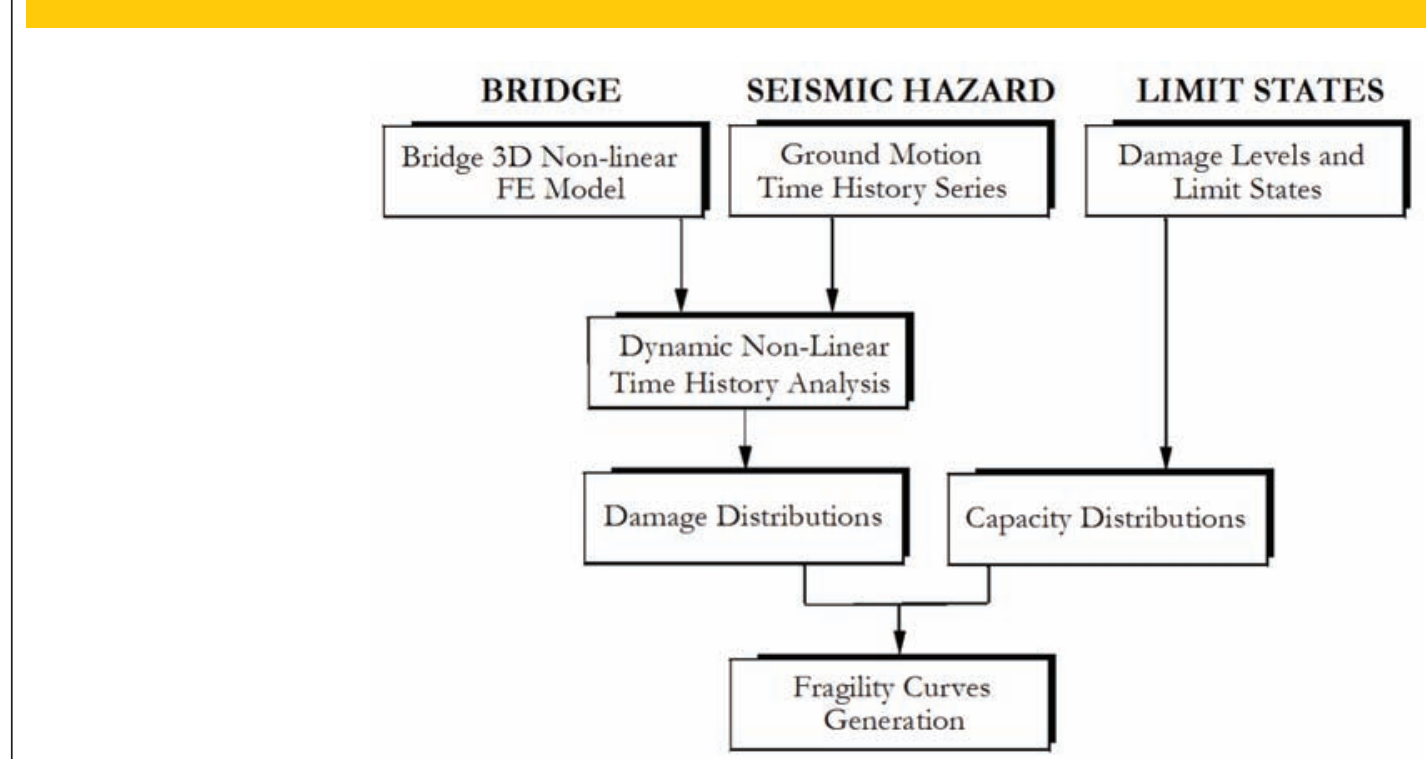

a function of a chosen ground-motion intensity measure (IM). ACcordingly to Choi et al. [8], if the structural capacity and the seismic demand are described by a lognormal distribution, the probability of reaching or exceeding a specific damage state will be log-normally distributed and the bridge-component fragility can be calculated in a closed form as follows.

$$
P[\mathrm{LS} \mid \mathrm{IM}]=\Phi\left[\frac{\ln \left(S_{D} / S_{C}\right)}{\sqrt{\beta_{D \mid I M}^{2}+\beta_{C}^{2}}}\right]
$$

Where $\Phi[\cdot]$ is the standard normal distribution function, $S_{D}$ is the mean structural demand, $S_{C}$ is the mean structural capacity, $\beta_{D \mid M}$ is the logarithmic standard deviation for the demand and $\beta_{c}$ is the logarithmic standard deviation for the capacity. In the analytical analyses, the seismic demand is described by probabilistic seismic demand models (PSDMs) given in terms of an appropriate intensity measure. The peak responses of 180 combined pairs of bridge/ground motion time history (GMTH) are plotted in terms of peak ground acceleration (PGA). Following the work of Cornell et al. [28], it is accepted that the estimation of the mean structural demand follows a power model $\left(S_{D}=a \cdot I M^{b}\right)$. In order to simplify the calculations, peak response values are projected into a lognormal space and the parameters of the power model are computed using a linear regression on the modified space following Equation 6 .

$$
\ln \left(S_{D}\right)=\ln (a)+b \cdot \ln (I M)
$$

In this equation, $a$ and $b$ are the unknown coefficients and $I M$ represents the intensity measure. From this regression, an estimate of the median demand is obtained. The logarithmic standard deviation $\left(\beta_{D \mid M}\right)$ of the demand can also be estimated from this regression analysis for each component (Equation 7), where $N$ is the number of simulations and $d_{i}$ is the peak demand of the component of interest.

$$
\beta_{D I M} \cong \sqrt{\frac{\sum\left(\ln \left(d_{i}\right)-\ln \left(a \cdot I M^{b}\right)\right)^{2}}{N-2}}
$$

Capacity estimates of bridge components have been defined to correspond to qualitative descriptions as presented in FEMA-HAZUS [29]. Specific measurable metric values (in terms of a median, $S_{C}$, and lognormal standard deviation, $\beta_{c}$ ) are attributed to each of the qualitative damage description and bridge component to generate a limit state (LS), which correspond to a particular level of anticipated bridge functionality. These limit state capacities are also considered to follow a lognormal distribution. The actual values and assumptions used during the analysis are presented later. Using the results of median demand values of various bridge components, a correlation matrix is obtained and used to generate a joint PSDM, as proposed by Nielson and DesRoches [27]. The correlation matrix reflects the overall dynamics of the bridge system. The system fragility is assessed through a Monte Carlo simulation using a series approximation for bridge-level failure analysis. The probability that the bridge system is at or beyond a particular limit state is therefore the union of the probabilities of the bridge components exceeding the same LS.

The parameters for the lognormal distribution representing the system fragility (median and lognormal standard deviation) are estimated through a regression analysis, allowing the assessment of the conditional probability to achieve various qualitative damage states. For as-built bridges, the response of columns, 
abutment wing walls and conventional elastomeric bearings on abutments are considered to calculate the system fragility. In the case of isolated bridges, conventional elastomeric bearings are replaced by natural rubber seismic isolator devices. In this case, the system fragility is calculated based on three different configurations for the clearance values in abutment wing walls (transverse direction): 1) considering the same clearance value of as-built configuration (25.4 mm); 2) considering a clearance value of $250 \mathrm{~mm}$; 3) and considering a gap of $25.4 \mathrm{~mm}$ with steel keeper plates to reduce the demand on the abutment wing walls.

\section{Bridge model simulation}

The Chemin des Dalles is a symmetric continuous bridge with $106.5 \mathrm{~m}$ long divided into three equally spaced spans and $13.2 \mathrm{~m}$ wide. The bridge pier bents are composed of three circular columns and a transverse beam joining column tops. Each column has a $0.914 \mathrm{~m}$ diameter and vertical under clearance of $6.2 \mathrm{~m}$.
The bents and abutments are supported by shallow foundations. In addition, wing walls compose the support system in seat type abutments. The superstructure is composed of a $0.165 \mathrm{~m}$ depth deck and six prestressed concrete girders directly connected to transverse beams at the bents and supported by elastomeric bearings in the abutments. Bent columns are rigidly connected to the shallow foundations in the left bent and free for rotation in the right one (Figure 1).

A 3D finite element model of this bridge is developed using OpenSees - Open System for Earthquake Engineering [30]. In OpenSees, a wide range of material models, section models, elements and solution algorithms are available allowing the analysis of nonlinear systems. The superstructure is represented by elastic beamcolumn elements, with six degrees of freedom per node. Vertical connections are represented by rigid elastic beam-columns elements. Transverse bent and columns are represented using nonlinear beam-columns elements. The columns sections are divided in fibers, 12 in the circular direction and 10 in the radial direction.

\section{Figure 6 - Chemin des Dalles bridge model details}
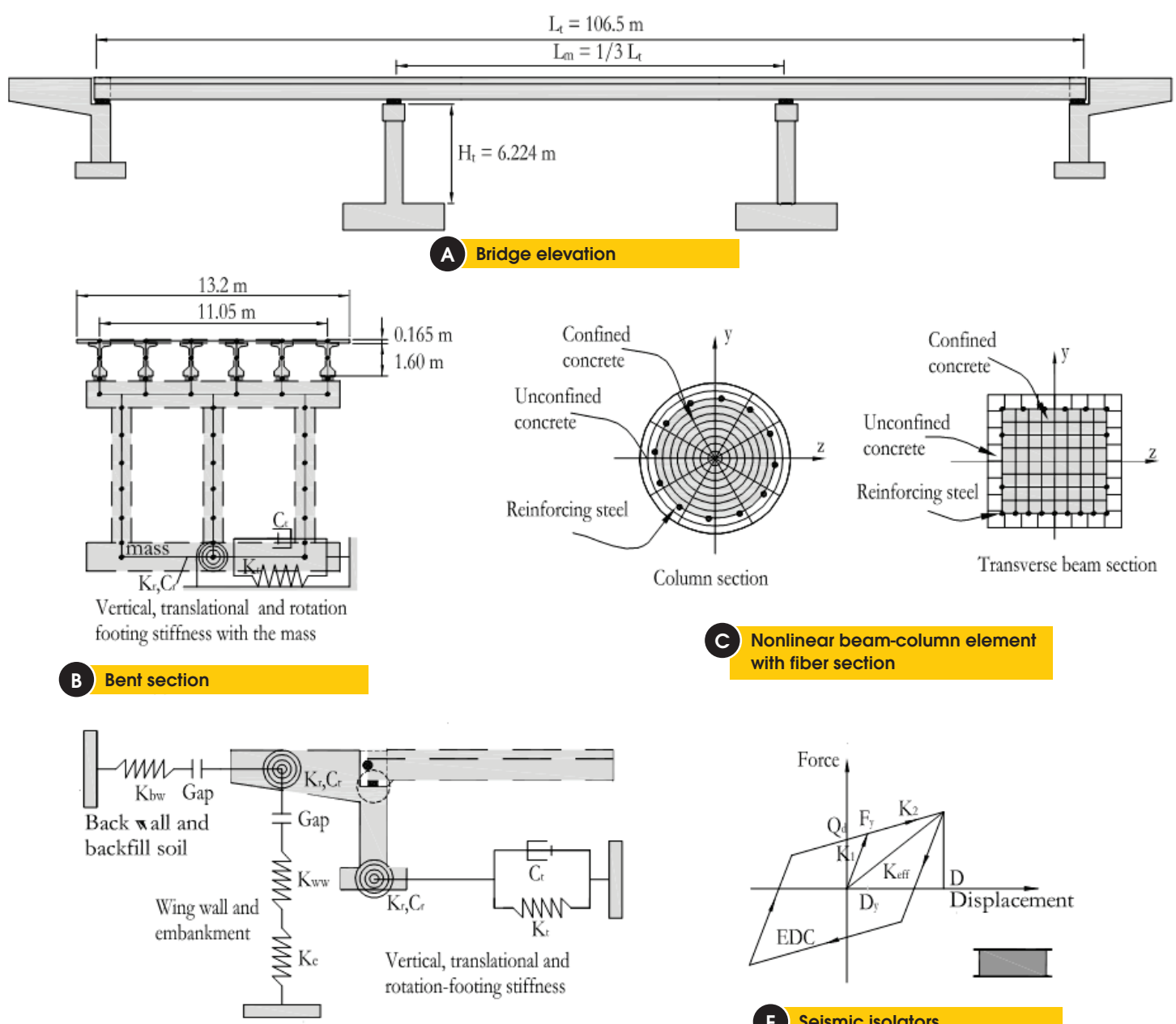

D Seat-type abutment

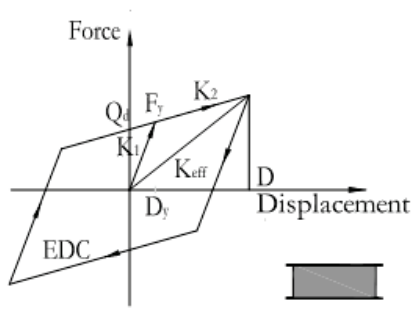

Seismic isolators 


\section{Figure 7 - Mean response spectrum and PGA distribution of the 180 synthetic ground motions}
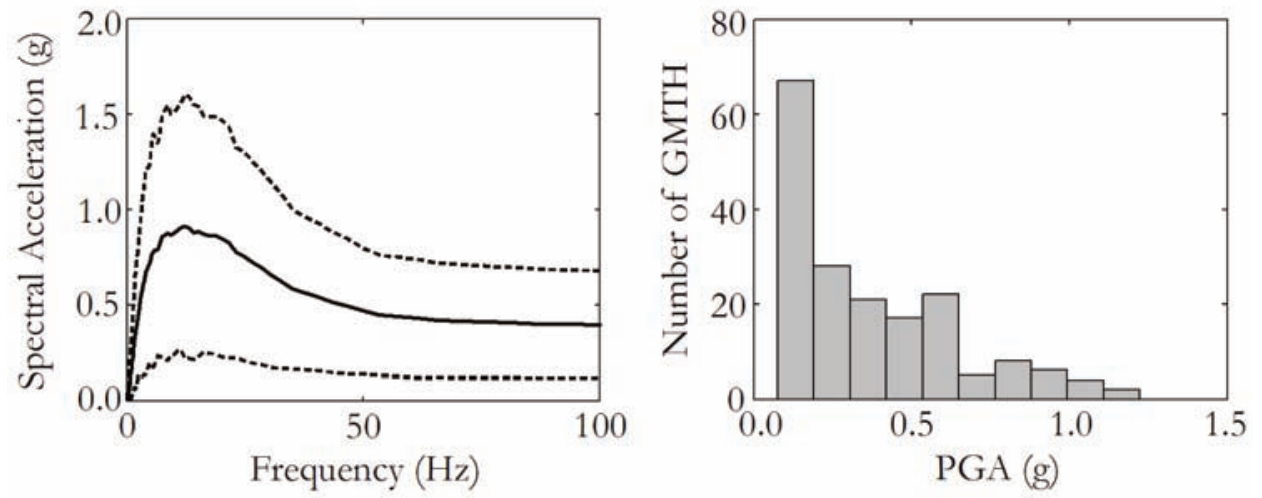

Regarding the shallow foundation, the soil foundation system is replaced by six compliance springs on the six degrees of freedom, accordingly to the CAN/CSA-S6-06 [14] recommendations, and viscous dampers that approximate the effects of radiation damping. In addition to the springs and dampers, the footing is represented by rigid beam-column elements to account for its geometry. The seat-type abutment is represented using translational and ro- tational springs that accounts for the interaction of the abutment walls, foundations and passive resistance of soil. The numerical model details of the bridge are presented in Figure 6, and more details can be found elsewhere [17].

The behavior of the elastomeric bearings and seismic isolation bearings are represented by a bilinear model in the horizontal directions. For the as-built bridge model, conventional elastomeric

\section{Figure 8 - Vibration periods and mode shapes for as-built and isolated models}

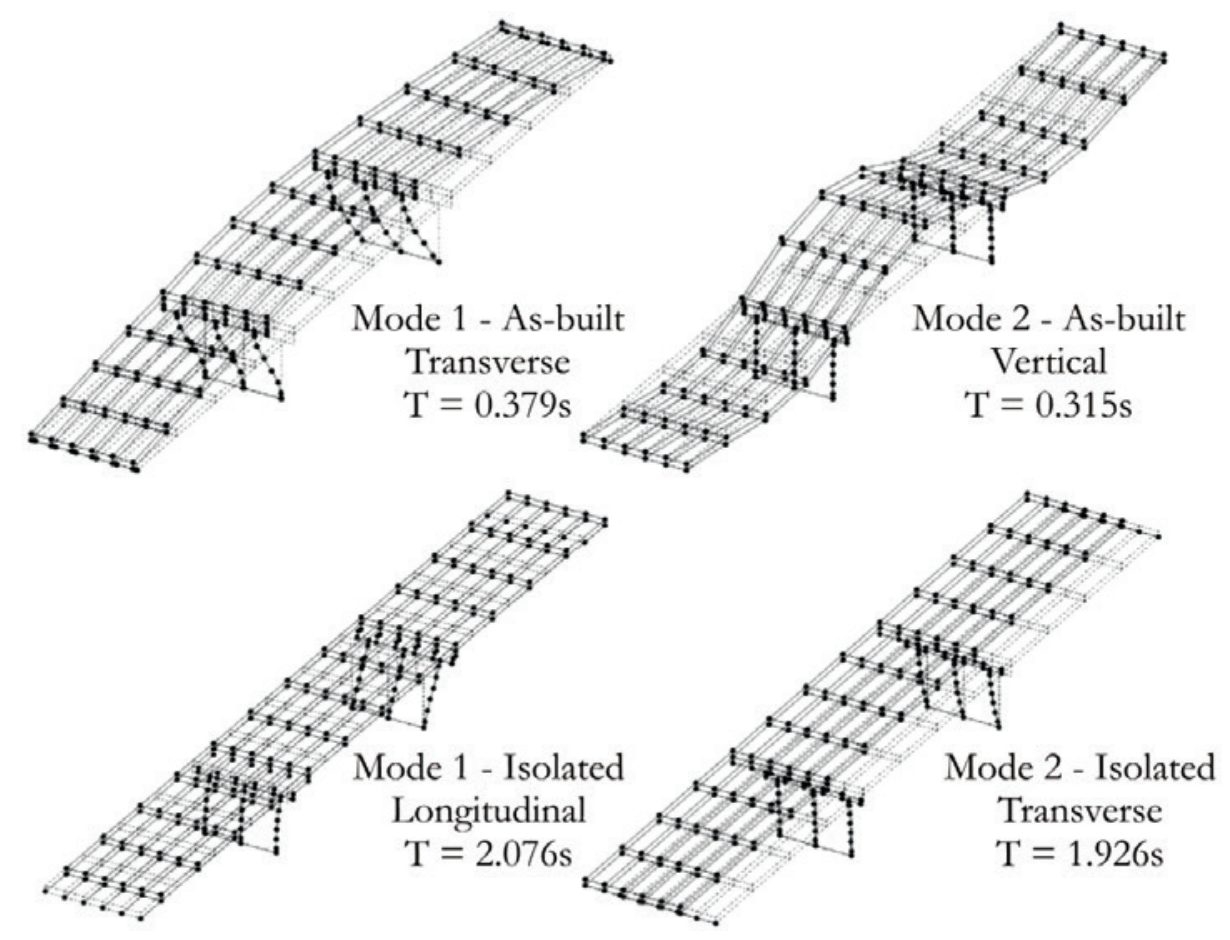


bearings were considered with an elasto-plastic behavior only on abutments, and a rigid connection is considered on bents between the longitudinal girders and the transverse beams [17]. For the retrofitted bridge model, natural rubber seismic isolators are considered on bents and abutments, replacing conventional elastomeric bearings and rigid connections. Due to the significant difference of weight supported by the seismic isolators placed on bents or abutments, two different configurations are considered for the isolation devices. For bents, the significant parameter values adopted to define the bilinear model are: $1.87 \mathrm{kN} / \mathrm{mm}$ for the elastic stiffness $\left(\mathrm{K}_{1}\right) ; 0.75 \mathrm{kN} / \mathrm{mm}$ for the post-yield stiffness $\left(\mathrm{K}_{2}\right)$; and $30 \mathrm{kN}$ for the yield force. In the case of abutment seismic isolators, the significant parameters are: $1.13 \mathrm{kN} / \mathrm{mm}$ for the elastic stiffness; $0.45 \mathrm{kN} /$ $\mathrm{mm}$ for the post-yield stiffness; and $20 \mathrm{kN}$ for the yield force $\left(F_{\mathrm{y}}\right)$. These values are obtained considering an isolated period around $2.0 \mathrm{~s}$ with effective stiffness values of $0.86 \mathrm{kN} / \mathrm{mm}$ and $0.52 \mathrm{kN} /$ $\mathrm{mm}$ for the isolator devices placed on bents and abutments, respectively, and a maximum displacement around $160 \mathrm{~mm}$ based on Equation 3.

\section{Input ground motions}

Representative ground motion time histories (GMTH) are necessary to represent the uncertainties inherent in seismic hazard to develop a reliable vulnerability assessment. Since few natural strong ground motions are available in Quebec, synthetic acceleration time histories are used. Atkinson [31] series of synthetic ground motions were chosen since they are compatible with the seismic hazard in Eastern Canada. These records are compatible with a probability of exceedance of $2 \%$ in 50 years (1/2500 years) and site class C of the NBCC [15]. They were developed using stochastic method and are able to capture uncertainties related to earthquake source, wave propagation, and soil conditions. The records generated for Eastern Canada are simulated for moment magnitudes $M_{w}=6$ and $M_{w}=7$. The peak ground acceleration (PGA) ranges from 0.1 to $1.2 \mathrm{~g}$.

For each magnitude, two fault-distance ranges were simulated: $\mathrm{M} 6$ at 10 to $15 \mathrm{~km}$ (M6 set 1) and 20 to $30 \mathrm{~km}$ (M6 set 2); and M7 at 15 to $25 \mathrm{~km}$ (M7 set 1) and 50 to $100 \mathrm{~km}$ (M7 set 2). Each set of records is composed of 45 GMTHs, for a total of 180 synthetics ground motions applied in the transverse direction for the non-linear time history analyses. Figure 7 shows the mean and standard deviation response spectrum and the distribution of the peak ground acceleration for all records available for Eastern Canada.

\section{Deterministic analysis}

To represent behavior differences of as-built and isolated bridges, a deterministic analysis is conducted. First, modal analyses for the as-built and isolated bridges with the predominant vibration periods and mode shapes are presented. Then, an illustrative nonlinear dynamic analysis is presented using two synthetic ground motion time histories, representative of magnitudes M6 and M7 events, to verify the differences in the seismic response of as-built and isolated models.

\subsection{Modal analysis}

The first two natural periods and mode shapes for as-built and seismic isolated bridge models are presented in Figure 8 . For the as-built model, in-situ dynamic results were used to calibrate the numerical model characteristics [16]. The first mode of vibration, for the as-built structure, is a transverse mode with a natural period of $0.379 \mathrm{~s}$. The second mode is a vertical mode and, in this case, is less important to the overall response of the bridge due to the force application only in the transverse direction. The third and fourth vibration modes of this bridge are

Figure 9 - Time history series used in analytical analysis
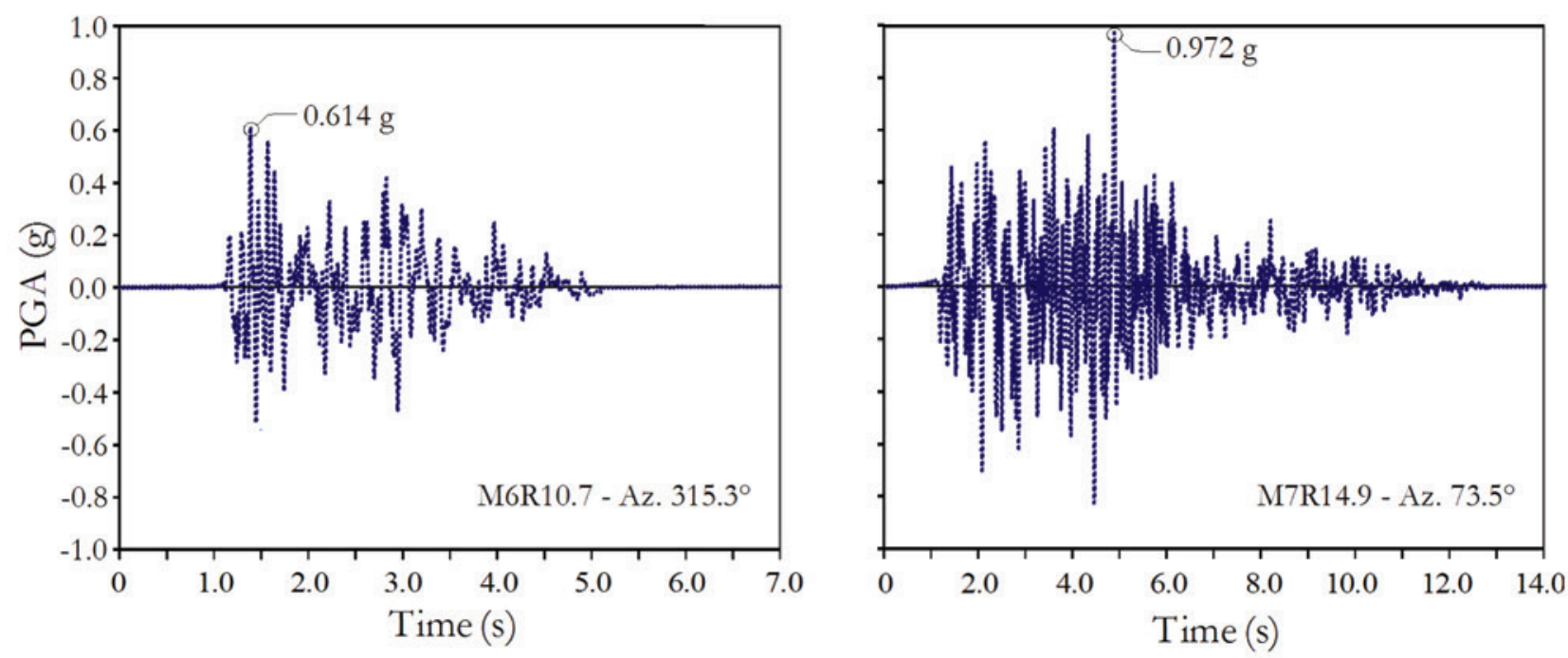
transverse and longitudinal modes, respectively.

In the case of the isolated bridge, as it can be seen in Figure 8, the first two vibrations modes are longitudinal and transversal modes with natural periods of $2.08 \mathrm{~s}$ and $1.93 \mathrm{~s}$, respectively. For the modal analysis, the effective stiffness of isolation devices was used instead of the bilinear characteristics.

\subsection{Time history analysis}

A dynamic analysis is conducted to compare the analytical results from the as-built and isolated bridges. The signal of the synthetic ground motion time histories used is presented in Figure 9. It simulates ground motions with magnitude 6.0 and 7.0 , with fault-

\section{Figure 10 - Summary of top column displacement, shear and moment distributions to a middle column}
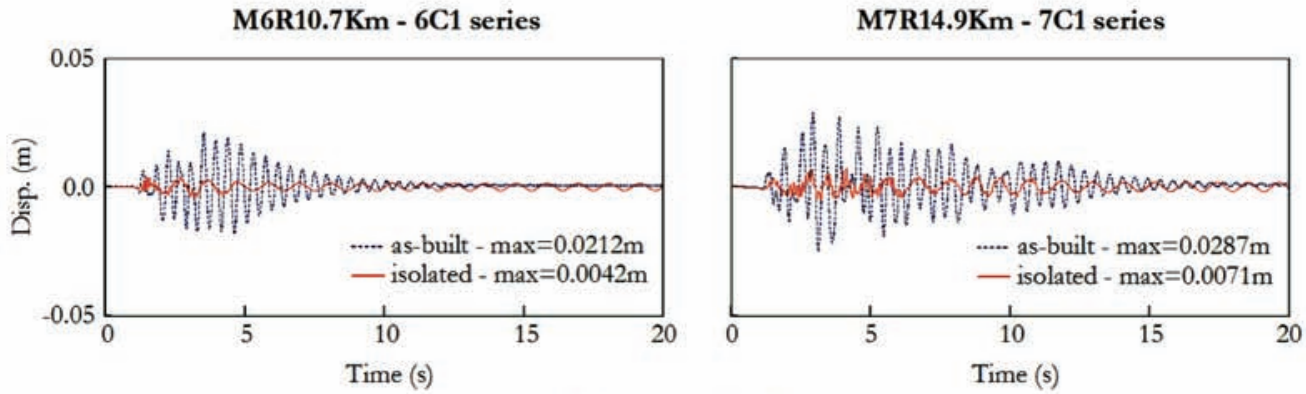

A Top column displacement
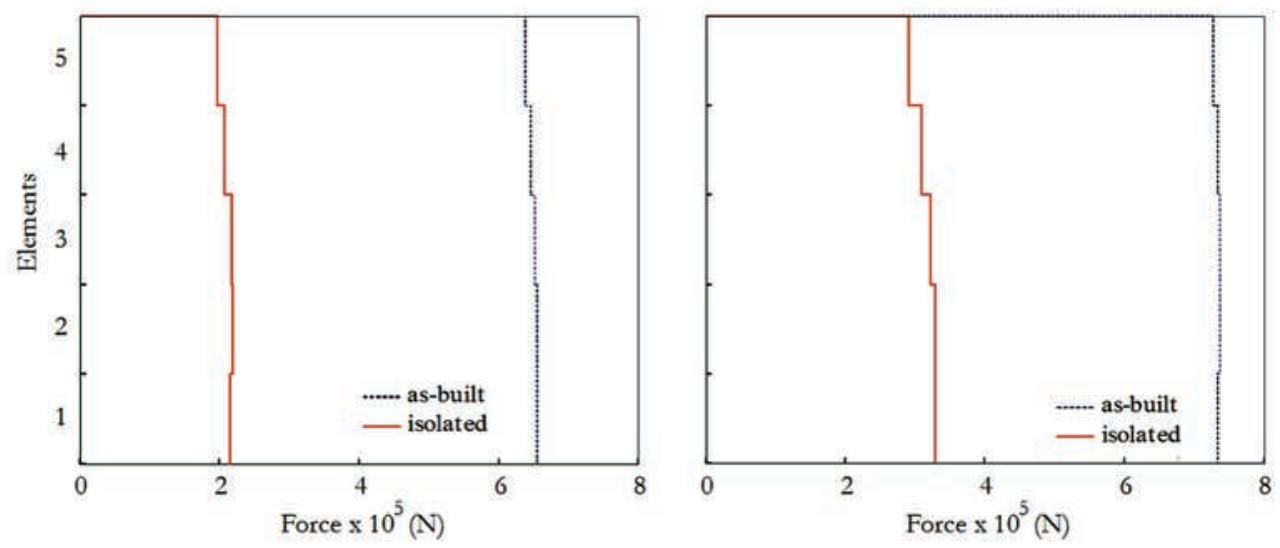

B Shear distribution
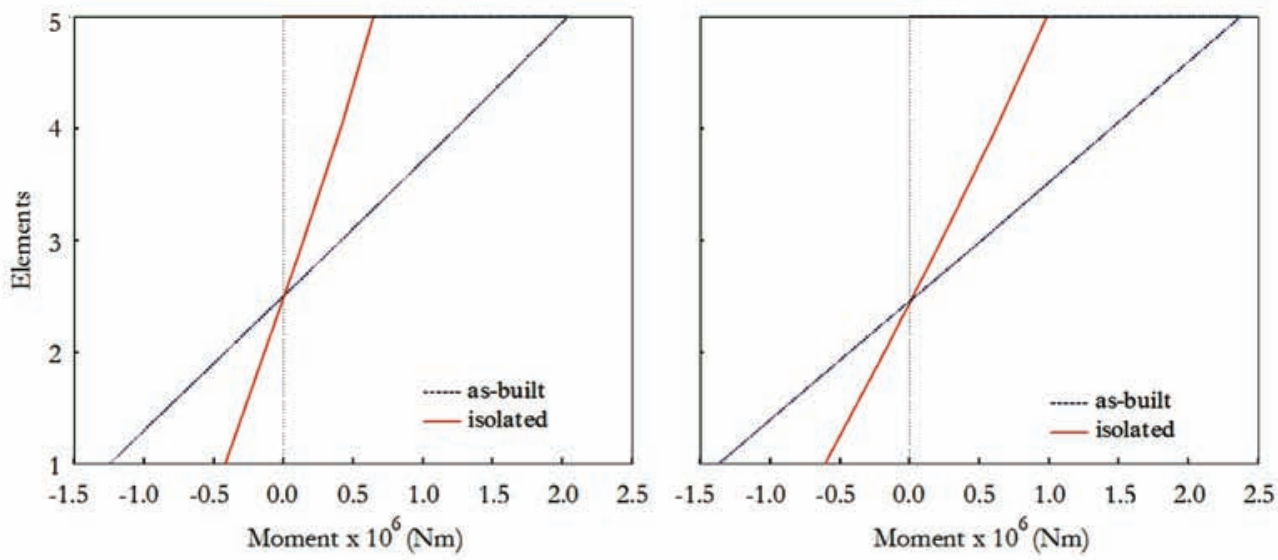

Moment distribution 
Figure 11 - PSDM comparison of median value of column displacement ductility

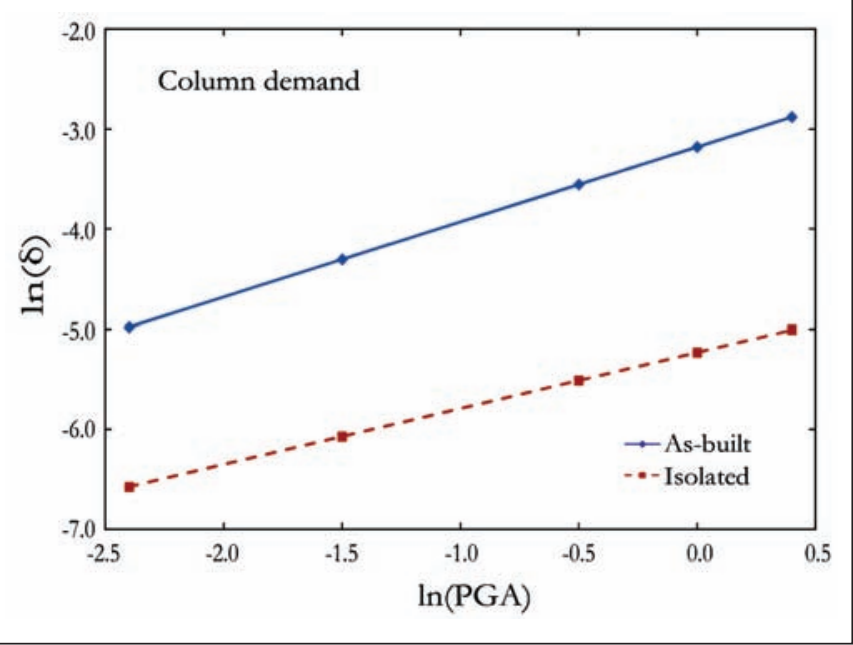

distances of $10.7 \mathrm{Km}$ and $14.9 \mathrm{Km}$, and peak ground accelerations of $0.614 \mathrm{~g}$ and $0.972 \mathrm{~g}$, respectively. To perform the numerical integration, the constant average acceleration Newmark's method with $1.5 \%$ Rayleigh damping at the first and second periods of vibration and time step of $0.002 \mathrm{~s}$ are used. Only the response in transverse direction is evaluated considering that the response of the Chemin des Dalles bridge is predominantly in this direction [16, 17] and due to the restrictions imposed by abutment back walls. A summary of top column displacements, shear and moment distributions for the as-built and isolated models are presented in Figure 10. The response is taken from a middle column of the bent with monolithic foundation connection. The top column displacements (Figure 11a) decrease considerably comparing the as-built and isolated models. A reduction as high as $75 \%$ is expected for top column displacements for both GMTH applied. In the case of shear and moment distributions (Figure 10b and Figure 10c), the effort levels decreased in the order of $63 \%$ for shear and $70 \%$ for moment distribution considering a M6 event. For a M7 event, the reductions observed are in the order of $56 \%$ for shear and $60 \%$ for moment distribution. One can note that the GMTHs applied are representative of an event with recurrence period of $1 / 2500$ years, which demonstrate the effectiveness of seismic isolation to improve the behavior and to reduce the risk of damage for isolated bridges. Further discussions about the effectiveness of seismic isolation will be held in a subsequent section.

\section{Capacity estimates}

The characterization of damage in one or more structural elements is an essential, not trivial, task in the definition of limit states (LS). Usually, the limit states adopted to develop fragility curves are associated with qualitative descriptions or functional interpretations, corresponding to an associated level of damage after an earthquake, such as slight, moderate, extensive and complete. Each LS can be interpreted as the expected performance level (i.e. the capacity) of different structural elements before it reaches a certain damage level. A description of the four qualitative damage states, adapted from HAZUS [4], is presented below:

- Slight (S): minor spalling at the column (damage requires no more than cosmetic repair), minor cracking and spalling of the abutments, minor spalling and cracking at hinges, or minor cracking of the deck;

- Moderate (M): any column experiencing moderate craking (shear cracks) and spalling, moderate movement of the abutment $(<50 \mathrm{~mm})$, any connection having cracked shear keys or bent bolts, rocker-bearing failure, or moderate settlement approach;

- Extensive (E): any column degrading without collapse (shear failure - structurally unsafe), significant residual movement at connections, major approach settlement, vertical offset of the abutment, or differential settlement at connections;

- Complete (C): any column collapsing and connections losing all bearing support, which may lead to imminent deck collapse or tilting of substructure caused by foundation failure.

In this study, the same median and lognormal standard deviation values of prescriptive limit states used by Tavares et al. [17] are adopted for columns, abutment walls and conventional elastomeric bearings. For columns, one of the most used parameter on fragility analysis is column displacement ductility, which is obtained by the ratio between the relative displacement at the top of a column and the relative displacement when a longitudinal reinforcing layer reaches the first yield. The values used are based on a study conducted specifically for the Chemin des Dalles bridge [32] using sectional analysis with damage mechanics layered finite elements. In the case of abutment walls, the first limit state is defined by the first yield, while the other limit states are defined based on the ultimate displacement of these components. Regarding the conventional elastomeric bearings, the first LS is defined by the loss of shear capacity (beginning of sliding) and the other limit states are defined by unseating of the bearings when the relative displacement exceeds a particular bearing dimension. In

\section{Table 1 - Limit-state capacities}

\begin{tabular}{|c|c|c|c|c|c|c|c|c|}
\hline \multirow{2}{*}{ Component } & \multicolumn{2}{|c|}{ Slight } & \multicolumn{2}{|c|}{ Moderate } & \multicolumn{2}{|c|}{ Extensive } & \multicolumn{2}{|c|}{ Complete } \\
\hline & Sc & $\mathrm{BC}$ & Sc & $\mathrm{BC}$ & Sc & $\mathrm{BC}$ & Sc & $\mathrm{BC}$ \\
\hline Column displacement ductility & 1.0 & 0.250 & 1.08 & 0.250 & 1.76 & 0.460 & 3.0 & 0.460 \\
\hline Abutment wing wall deformation (mm) & 7.0 & 0.250 & 15.0 & 0.250 & 30.0 & 0.460 & 60.0 & 0.460 \\
\hline Conventional elastomeric bearing ( $\mathrm{mm}$ ) & 30.0 & 0.250 & 60.0 & 0.250 & 150.0 & 0.460 & 300.0 & 0.460 \\
\hline Seismic isolators, shear strain (\%) & - & - & - & - & - & - & 267.0 & 0.460 \\
\hline
\end{tabular}


Table 2 - Bridge component and system fragility

\begin{tabular}{|c|c|c|c|c|c|c|c|c|c|}
\hline \multirow{2}{*}{ Bridge Class } & \multirow{2}{*}{ Component } & \multicolumn{2}{|c|}{ Slight } & \multicolumn{2}{|c|}{ Moderate } & \multicolumn{2}{|c|}{ Extensive } & \multicolumn{2}{|c|}{ Complete } \\
\hline & & Med & Disp & Med & Disp & Med & Disp & Med & Disp \\
\hline \multirow{4}{*}{ As-built } & Column & 0.608 & 0.526 & 0.774 & 0.526 & 1.287 & 0.734 & $\mathrm{~N} / \mathrm{A}$ & - \\
\hline & Abutment wing wall & $\mathrm{N} / \mathrm{A}$ & - & $\mathrm{N} / \mathrm{A}$ & - & $\mathrm{N} / \mathrm{A}$ & - & $\mathrm{N} / \mathrm{A}$ & - \\
\hline & Elastomeric bearing & 1.020 & 0.470 & $\mathrm{~N} / \mathrm{A}$ & - & $\mathrm{N} / \mathrm{A}$ & - & N/A & - \\
\hline & System & 0.588 & 0.506 & 0.763 & 0.515 & 1.129 & 0.673 & $\mathrm{~N} / \mathrm{A}$ & - \\
\hline \multirow{4}{*}{$\begin{array}{c}\text { Isolated } \\
\text { (gap-25,0 mm) }\end{array}$} & Column & N/A & - & N/A & - & $\mathrm{N} / \mathrm{A}$ & - & $\mathrm{N} / \mathrm{A}$ & - \\
\hline & Abutment wing wall & 1.605 & 0.950 & $\mathrm{~N} / \mathrm{A}$ & - & $\mathrm{N} / \mathrm{A}$ & - & $\mathrm{N} / \mathrm{A}$ & - \\
\hline & Seismic isolator & $\mathrm{N} / \mathrm{A}$ & - & $\mathrm{N} / \mathrm{A}$ & - & $\mathrm{N} / \mathrm{A}$ & - & $\mathrm{N} / \mathrm{A}$ & - \\
\hline & System & 1.585 & 0.929 & $\mathrm{~N} / \mathrm{A}$ & - & $\mathrm{N} / \mathrm{A}$ & - & $\mathrm{N} / \mathrm{A}$ & - \\
\hline \multirow{4}{*}{$\begin{array}{c}\text { Isolated } \\
\text { (gap }-250,0 \mathrm{~mm})\end{array}$} & Column & N/A & - & N/A & - & N/A & - & N/A & - \\
\hline & Abutment wing wall & N/A & - & $\mathrm{N} / \mathrm{A}$ & - & N/A & - & $\mathrm{N} / \mathrm{A}$ & - \\
\hline & Seismic isolator & $\mathrm{N} / \mathrm{A}$ & - & $\mathrm{N} / \mathrm{A}$ & - & $\mathrm{N} / \mathrm{A}$ & - & $\mathrm{N} / \mathrm{A}$ & - \\
\hline & System & N/A & - & $\mathrm{N} / \mathrm{A}$ & - & $\mathrm{N} / \mathrm{A}$ & - & N/A & - \\
\hline \multirow{4}{*}{$\begin{array}{c}\text { Isolated } \\
\text { (keeper plates) }\end{array}$} & Column & N/A & - & N/A & - & N/A & - & N/A & - \\
\hline & Abutment wing wall & 1.834 & 0.745 & $\mathrm{~N} / \mathrm{A}$ & - & N/A & - & $\mathrm{N} / \mathrm{A}$ & - \\
\hline & Seismic isolator & N/A & - & N/A & - & N/A & - & $\mathrm{N} / \mathrm{A}$ & - \\
\hline & System & 1.764 & 0.735 & N/A & - & $\mathrm{N} / \mathrm{A}$ & - & $\mathrm{N} / \mathrm{A}$ & - \\
\hline
\end{tabular}

the case of seismic isolators, the values adopted here are the same used in Siqueira et al. [33], where the derivation of the limit states was based on experimental results combined with finite element analyses. It is important to note that only complete damage is adopted for seismic isolator in the convolution of system fragility since no sign of intermediate damage was observed experimentally. The complete LS for seismic isolator was based on bearing instability corresponding to $267 \%$ of shear strain. More details about the experimental results and damage of seismic isolators can be found in Siqueira [34]. Table 1 presents the limit states for all components considered in terms of median $\left(S_{C}\right)$ and lognormal standard deviation or dispersion $\left(\beta_{c}\right)$.

\section{Fragility results}

Using the methodology presented earlier, fragility curves for the Chemin des Dalles bridge are developed comparing the as-built

\section{Figure 12 - Component controlling fragility comparison}

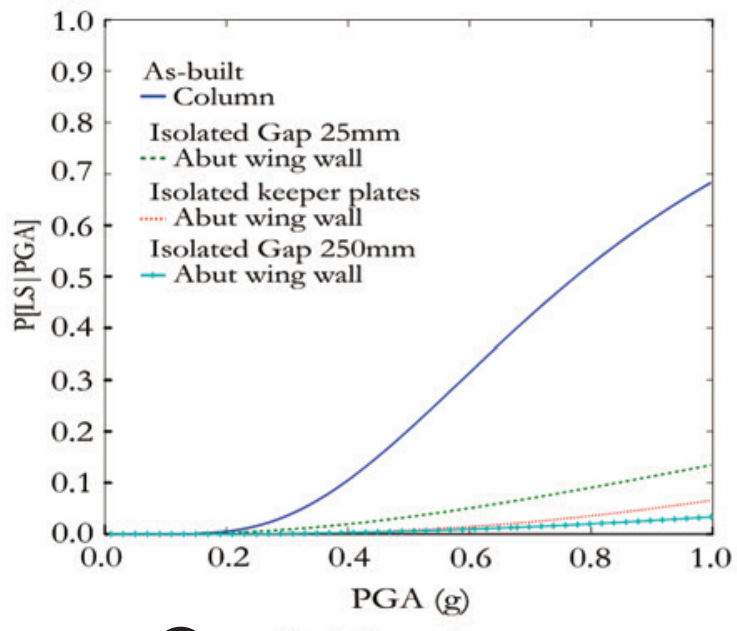

LS moderate

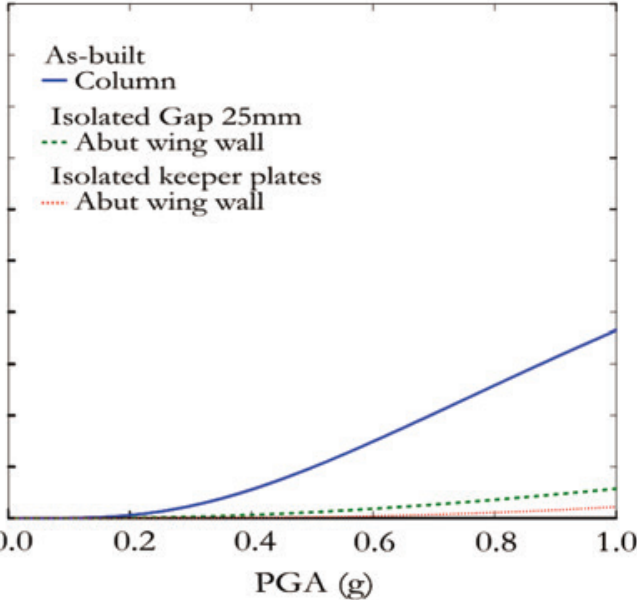

B LS extensive 
and retrofitted configurations to assess the impact of seismic isolation as a retrofit measure. The first step for a seismic vulnerability assessment is the definition of the seismic demand. The seismic demand is assessed by constructing PSDMs for the response of critical bridge components, in which their potential nonlinear behavior are considered in the 3-D analytical analysis. The changes in the values of the constitutive components of each PSDM have an impact on the fragility curves results, since these changes affect directly the seismic demand. A comparison of regression lines for column displacement ductility is presented in Figure 11 for as-built and isolated model with gap of $25.4 \mathrm{~mm}$.

Comparing the as-built and isolated configurations, one can see that the demand placed on columns is significantly reduced when seismic isolation is considered. In the study of Tavares et al. [17], the fragility of the Chemin des Dalles bridge was found to be governed by column vulnerability, and this significant reduction on col- umn demand suggests the effectiveness of seismic isolation as a retrofit measure for this bridge.

Fragility curves for the component level and bridge system level analyses are presented in Table 2 for as-built and seismic isolated configurations. A comparison for the component controlling fragility for as-built and isolated models is presented in Figure 12 for moderate and extensive damages. The component controlling fragility in the case of as-built model is columns for all damage levels, which is consistent with the results of Tavares et al. [17]. In the case of isolated bridges models, the component controlling fragility is the abutment wing wall. This behavior change is expected since seismic isolators are designed to reduce the demand placed on columns, and the higher flexibility introduced in the system increases deck displacements, increasing the demand placed on wing walls. It is important to note that in the case of isolated model with clearance of $250 \mathrm{~mm}$, which simulates a situation

\section{Figure 13 - Bridge-system fragility curves comparison}
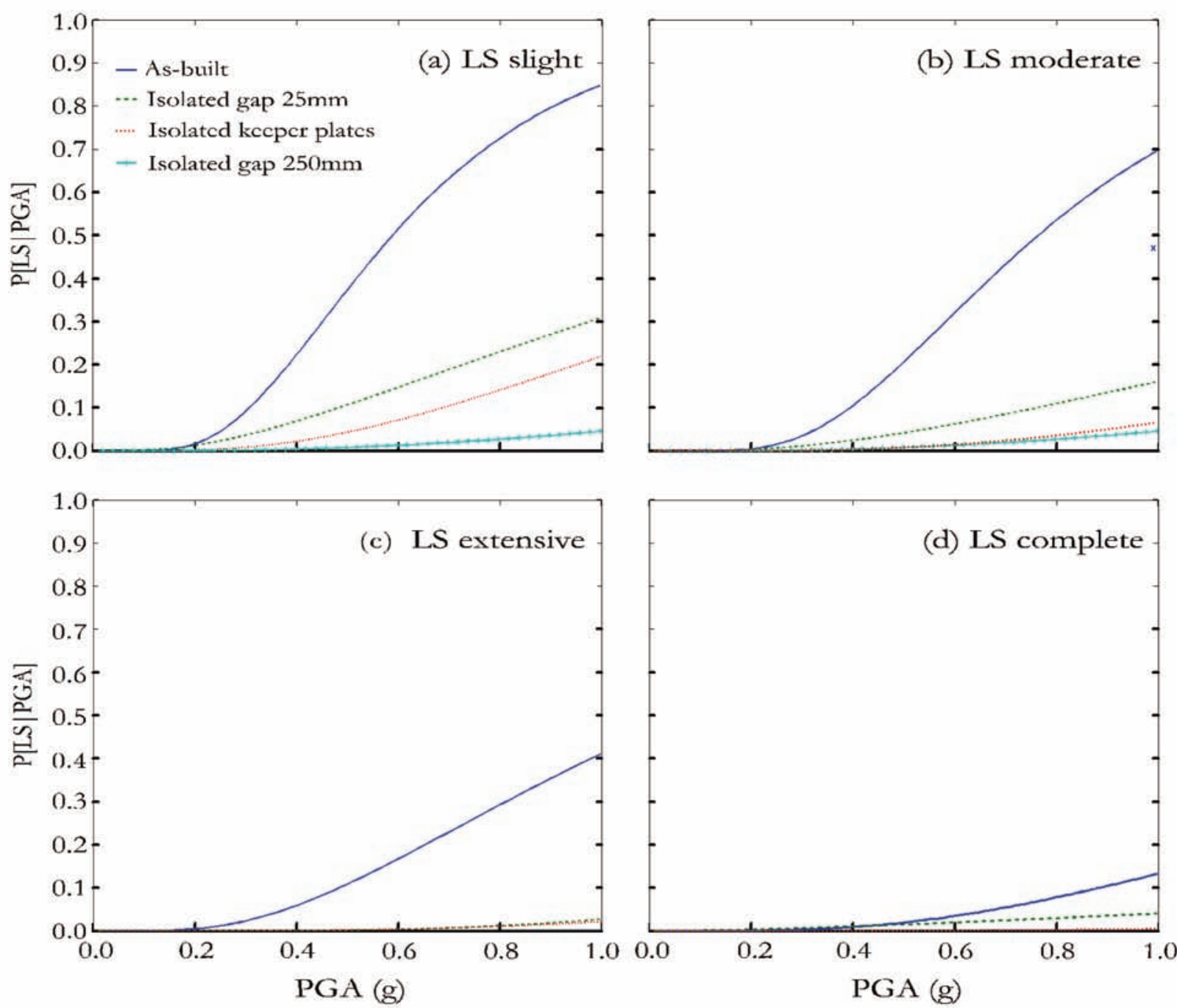
where the lateral clearances respects the indication presented in the design code [14], the fragility upon bridge components can be considered as irrelevant since they are on a level lower than $5 \%$ for the extreme PGA value. For existent bridges, which is the case of the Chemin the Dalles bridge, an alternative solution to reduce the level of changes in the structure of the bridge on the abutment's region is the use of steel keeper plates. As it can be observed in table 2 and Figure 12, this solution can reduce the fragility placed upon abutment these components to acceptable levels.

Fragility curves for the bridge-system level are plotted in Figure 13. These fragility curves offer an effective approach to evaluate the impact of seismic isolation as retrofit measure for the Chemin des Dalles bridge. Figure 13 depicts a clear decrease in the fragility for the isolated models which can be observed comparing to the as-built ones. For an earthquake with a PGA of $0.5 \mathrm{~g}$, for example, there is a probability around $40 \%$ of slight damage for the as-built configuration. In the case of isolated configurations, system fragility is reduced to around $12 \%$ for a model with gap of $25 \mathrm{~mm}$ and to less than $5 \%$ to the other configurations. Considering moderate damage, as-built fragility is around $21 \%$ and isolated fragilities are reduced to values lower than $5 \%$. In the case of extensive damage, as-built fragility is around $12 \%$ and isolated fragilities are reduced to values lower than $5 \%$. Complete damage is not expected in all bridge configurations. Regarding the results of the Table 2, due to the high correlation between the response of the components, one can see that the system fragility approaches the fragility of the most fragile component, which leads to some advantage in terms of bridge performance after an earthquake. For example, considering performance levels described by the limit states, even if the wing walls are damaged after an earthquake, the system keep their functionality due to the integrity of columns and foundations, and less time and cost to restore bridge integrity is expected.

\section{Conclusions}

Analytical fragility curves are used to evaluate the seismic vulnerability of a typical concrete bridge in Quebec, Canada. The as-built and the isolated bridge models are compared, evidencing the effectiveness of seismic isolation as a retrofit for the Chemin des Dalles bridge. Analytical deterministic analysis are conducted to compare the response of the Chemin de Dalles bridge column's submitted to ground motions representative of magnitudes M6 and M7 with fault distances varying from 10 to $15 \mathrm{Km}$. To assess the fragility of this bridge, 3-D analytical models subjected to a suite of synthetic GMTHs compatible with a uniform hazard spectrum with a probability of exceedance of $2 \%$ in 50 years were used. The methodology for assessing the fragility used in this study incorporates the contribution of multiple vulnerable components for system fragility estimation.

The effectiveness of the seismic isolators in the increase of the Chemin des Dalles bridge seismic performance can be seen in all the analysis performed throughout this study. The response of the deterministic nonlinear dynamic analysis demonstrates a decrease on column solicitations in order of $60 \%$ to shear and $65 \%$ to moment distributions when seismic isolators are considered. The displacements are reduced in order of $75 \%$. The intermediate analysis of components fragility offers an insight on the impact of seismic isolation in the demand placed on various components of the system. Generally, the use of seismic isolators significantly reduces the demand placed on key elements as columns.

The component that governs the fragility of the bridge studied changed from the column to the abutment wing wall. Isolated bridges tend to have their behaviour governed by the abutment wing walls. Moreover, the analysis of the fragility in the component level shows the importance of the adequate clearance (gap) in the wing walls to increase the effectiveness of this isolation system for new bridges. And, for existing bridges, one effective solution to reduce the demand placed on abutment wing walls is to consider steel keeper plates, reducing the level of structural and geometric changes for seismic isolated bridges configurations.

The system bridge fragility analysis demonstrated the effectiveness of seismic isolation as a retrofit measure for the Chemin des Dalles bridge considerably reducing system fragility for the different damage levels considered. The correlation of bridge components response also demonstrates that the overall system fragility is controlled by the fragility of abutment wing walls. This leads to an advantage in terms of bridges performance after an earthquake. Protecting key components of the bridge system, as columns and foundations, leads to less time to restore the complete functionality of the bridge and less probability of restriction in the traffic or the bridge closure after an extreme event.

\section{Acknowledgements}

The authors acknowledge the financial support of the Natural Sciences and Engineering Research Council of Canada (NSERC) for the Canadian Seismic Research Network (CSRN), the Québec Fonds pour la recherche sur la nature et les technologies (FQRNT) for the Centre d'études interuniversitaires des structures sous charges extrêmes (CEISCE), and Transports Québec. Computational resources for this work were provided by Compute Canada through the Réseau québécois de calcul de haute performance (RQCHP)

\section{References}

[01] BASÖZ, N.I.; KIREMIDJIAN, A.S. Evaluation of Bridge Damage Data from the Loma Prieta and Northridge, California Earthquakes. Technical Report, MCEER-98-004, Multidisciplinary Center for Earthquake Engineering Research, State University of New York at Bu_alo, NY. 1998.

[02] TQ. Manuel d'inspection des structures : évaluation des dommages. Ministère des Transports du Québec, Bibliothèque Nationale du Québec, Gouvernement du Québec, Canada. 1995.

[03] TAVARES, D.H.; PADGETT, J.E.; PAULTRE, P. Fragility curves of typical as-built highway bridges in Eastern Canada. Engineering Structures 2012; 40:107-118.

[04] FEMA. HAZUS-MH MR3, multi-hazard loss estimation methodology: earthquake model. Technical manual, Federal Emergency Management Agency, Washington DC, 2003.

[05] BASÖZ, N.I.; KIREMIDJIAN, A.S, KING, S.A.; LAW, K.H. Statistical analysis of bridge damage data from the 1994 Northridge, CA, Earthquake. Earthquake Spectra 1999; 15(1):25-54.

[06] SHINOZUKA, M.; FENG, M.Q.; LEE, J.; NAGANUMA, T. Statistical analysis of fragility curves. Journal of Engineering Mechanics 2000; 126(12):1224-1231. 
[07] HWANG, H.M.; JERNIGAN, J.B.; LIN, Y.W. Evaluation of seismic damage to Memphis bridges and highway systems. Journal of Bridge Engineering 2000; 5(4):322-330.

[08] CHOI, E.; DESROCHES, R; NIELSON, B. Seismic fragility of typical bridges in moderate seismic zones. Engineering Structures 2004; 26(2):187-199.

[09] NIELSON, B.G.; DESROCHES, R. Analytical seismic fragility curves for typical bridges in the Central and Southeastern United States. Earthquake Spectra 2007; 23(3):615-633.

[10] PAN, Y.; AGRAWAL, A.K.; GHOSN, M. Seismic fragility of continuous steel highway bridges in New York State. Journal of Bridge Engineering 2007; 12(6):689-699.

[11] SHINOZUKA, M.; KIM, S.H.; KUSHIYAMA, S.; YI, J.H. Fragility curves of concrete bridges retrofitted by column jacketing. Earthquake Engineering and Engineering Vibration 2002; 1(2):195-205.

[12] PADGETT, J.E.; DESROCHES, R. Retrofitted bridge fragility analysis for typical classes of multispan bridges. Earthquake Spectra 2009; 25(1):117-141.

[13] AGRAWAL, A.K.; GHOSN, M.; ALAMPALLI, S; PAN, Y. Seismic fragility of retrofitted multispan continuous steel bridges in New York. Journal of Bridge Engineering 2012; 17(4):562575.

[14] CAN/CSA-S6-06. Canadian Highway Bridge design code. Canadian Standards Association (CSA), Mississauga, ON, Canada, 2006.

[15] NRCC. National Building Code of Canada. National Research Council of Canada, 2010.

[16] ROY, N.; PAULTRE, P.; PROULX, J. Performance-Based Seismic Retrofit of a Bridge Bent: Design and Experimental Validation. Canadian Journal of Civil Engineering, 37:367379, 2010.

[17] TAVARES, D.H.; SUESCUN, J.R.; PAULTRE, P.; PADGETT, J.E. Seismic Fragility of a Highway Bridge in Quebec. Journal of Bridge Engineering, Vol. 18, No. 11, November 1, 2013.

[18] FIB. Seismic bridge design and retrofit - structural solutions. Technical Report, Bulletin 39, Fédération Internationale du Béton, 2007.

[19] KELLY, J.M.. Earthquale-Resistant Design With Rubber Springer, London, 1997.

[20] DESROCHES, R.; CHOI, E.; LEON, R.T.; PFEIFER, T.A. Seismic Response of Multiple Span Steel Bridges in Central and Southeastern United States. II: Retrofitted. Journal of Bridge Engineering, 9(5):473-479, 2004.

[21] AMERICAN ASSOCIATION OF STATE HIGHWAY AND TRANSPORTATIONS OFFICIALS (AASHTO). Guide Specifications for Seismic Isolation Design. Washington, DC, 1999.

[22] NAEIM, F.; KELLY, J.M.. Design of seismic isolated structures: from theory to practice. Mechanical characteristics and modeling of isolators, Wiley, New York, 1999.

[23] HIGHWAY INNOVATIVE TECHNOLOGY EVALUATION CENTER (HITEC). Summary of Evaluation Findings for the Testing of Seismic Isolation and Energy Dissipating Devices. CERF Report, Washington, DC, 1999.

[24] PADGETT, J. E. Seismic Vulnerability Assessment of Retrofitted Bridges using Probabilistic Methods. Ph.D. Thesis, Georgia Institute of Technology, 2007.
[25] ZHANG, J.; HUO, Y. Evaluating effectiveness and optimum design of isolation devices for highway bridges using the fragility function method. Engineering Structures, 31:16481660, 2009.

[26] MORI A.; CARR, A.J.; COOKE, N.; MOSS, P.J. Compression behaviour of bridge bearings used for seismic isolation. Engineering Structures, Vol. 18, No. 5, 1996.

[27] NIELSON, B.G.; DESROCHES, R. Seismic fragility methodology for highway bridges using a component level approach. Earthquake Engineering \& Structural Dynamics 2007; 36(6):823-839.

[28] CORNELL, C.A.; JALAYER, F.; HAMBURGER, R.O.; FOUTCH, D.A. Probabilistic basis for 2000 sac federal emergency management agency steel moment frame guidelines. Journal of Structural Engineering 2002; 128(4):526-533.

[29] FEDERAL EMERGENCY MANAGEMENT AGENCY (FEMA). Hazus-mh mr1 : Technical manual, 2003.

[30] MAZZONI, S.; McKENNA F.; SCOTT, M.H.; FENVES, G.L. Open system for earthquake engineering simulation user command-language manual, opensees version 2.0. Technical Report, Pacific Earthquake Engineering Research Center, University of California, Berkeley 2009.

[31] ATKINSON, G.M.. Earthquake time histories compatible with the 2005 NBCC uniform hazard spectrum. Can. J. Civ. Eng., 36(6), 991- 1000, 2009.

[32] TAVARES, D.H.; CARDONA, L.; PAULTRE, P. Bridge reinforced concrete column limit state definition. In Anais do $52^{\circ}$ Congresso Brasileiro do Concreto, Fortaleza, 2010.

[33] SIQUEIRA, G.H.; SANDA, A.S.; PAULTRE, P; PADGETT, J.E. Fragility curves for isolated bridges in eastern Canada using experimental results. (In Press) Eng Struct (2014), http://dx.doi.org/10.1016/j.engstruct.2014.04.053

[34] SIQUEIRA, G.H. Évaluation de la vulnérabilité sismique des ponts routiers au Québec réhabilités avec l'utilisation d'isolateurs en caoutchouc naturel. PhD Thesis, Faculté de Génie, Département de Génie Civil, Université de Sherbrooke, Sherbrooke, Québec, Canada, 2013. 